\title{
Modeling of a planar SOFC performances using artificial neural network
}

\author{
N. A. Zambri ${ }^{1}$, Norhafiz Salim ${ }^{2}$, A. Mohamed ${ }^{3}$, Ili Najaa Aimi Mohd Nordin ${ }^{4}$ \\ ${ }^{1,4}$ Faculty of Engineering Technology, Universiti Tun Hussein Onn Malaysia Kampus Pagoh, Malaysia \\ ${ }^{2}$ Faculty of Electrical Engineering, Universiti Teknikal Malaysia Melaka, Malaysia \\ ${ }^{3}$ Department of Electrical, Electronic and Systems Engineering, Faculty of Engineering and Built Environment, \\ Universiti Kebangsaan Malaysia, Malaysia
}

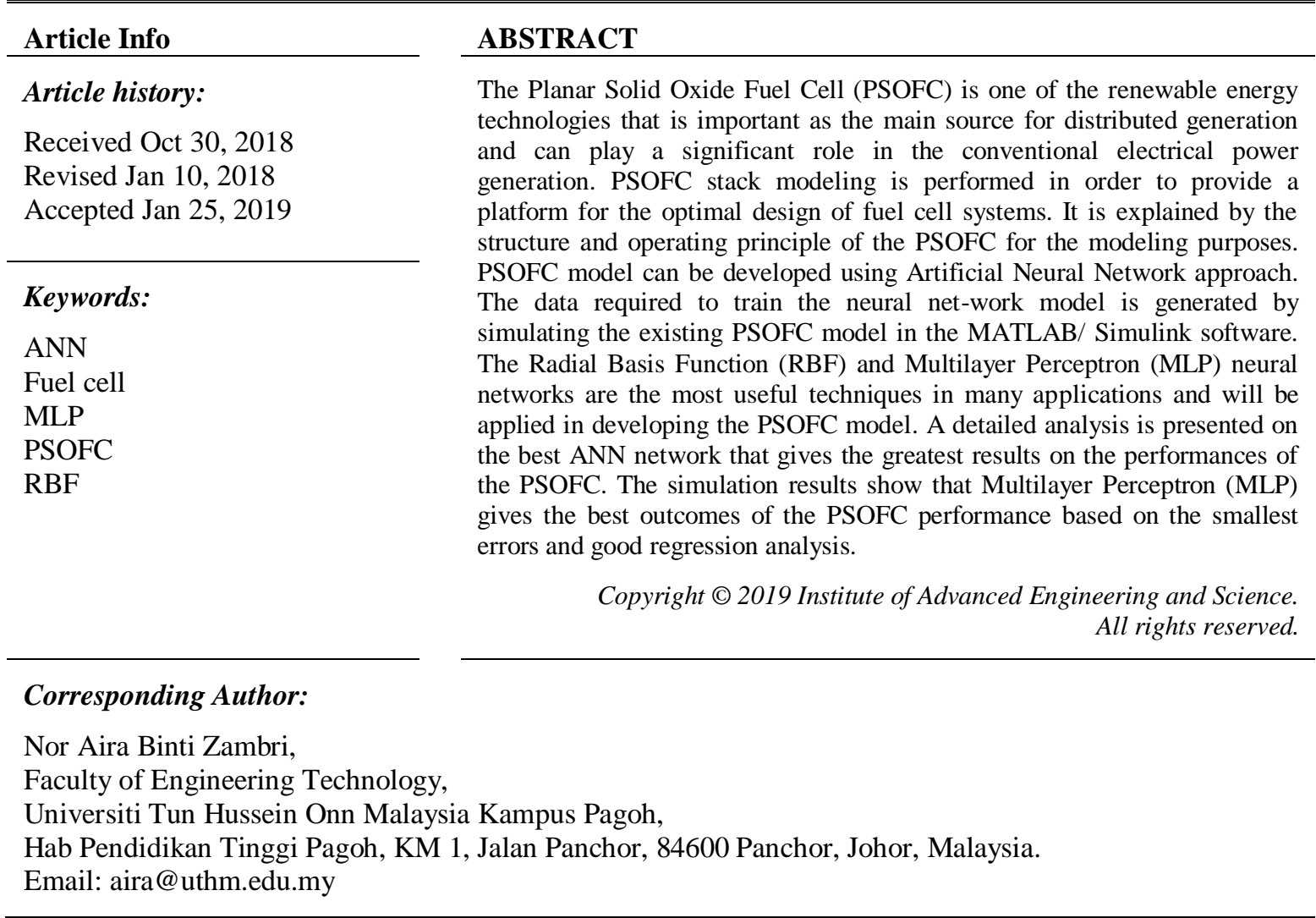

\section{INTRODUCTION}

The development of fuel cell as a renewable energy technology has become very popular due to its clean and sustainable sources of electrical energy and produces pure energy with comparatively high efficiency and effectively [1-3]. A fuel cell is a device that converts the chemical energy from a fuel such as methane into electrical energy for power applications through a chemical reaction of oxygen or any oxidizing agent with a positively charged hydrogen ions inside the cell [4]. It can be categorized as a first-rate electricity source because of its ability in producing continuous and constant power at full load. A fuel cell generation system needs oxygen and hydrogen in performing the chemical reaction inside the stack and produce electricity in DC form [5]. There are at least four fuel cell types have evolved in the past decades and becoming popular due to the clean and silent system. Fuel cell types are differentiate after their electrolyte, the substance that transports the ions and also dictates the operating temperature of a fuel cell types [6]. Depending on the operating temperature, a specific catalyst is chosen to oxidize the fuel such as Molten Carbonate Fuel Cell (MCFC), Phosphoric Acid Fuel Cell (PAFC), Solid Oxide Fuel Cell (SOFC) and Proton Exchange Membrane Fuel Cell (PEMFC). MCFC and SOFC operates at higher temperature and have the ability of internal fuel reformation that allows numerous fuel options. SOFC model can be divided into two main types, namely, tubular and planar configuration types. Tubular SOFC are formed into stacks by 
implementing a tube sheet to support tubes, whereas the planar configuration is formed by a thin plate cells sandwiched between metal interconnecting plates [7]. Advantages of both types normally depend on their physical configurations. The tubular configuration is a matured technology which promises robustness, resistance to mechanical damage, and also has a simpler sealing, whereas the planar design is more compact and has a high power density, which decreases material content, thus lowering cost. Some tubular designs eliminate the need for seals and allow for thermal expansion. The tubular SOFC operates between $900^{\circ} \mathrm{C}$ $1000^{\circ} \mathrm{C}$ but planar operates at $800^{\circ} \mathrm{C}$ or even below and this main criteria effect the development cost of tubular SOFC which is normally higher $[8,9]$ and the thermal safety for tubular SOFC is quite challenging $[10,11]$. In order to achieve high efficiency, planar SOFC normally consists of an ultra-thin electrode or electrolyte sheets with low electrical resistance. Operation at temperature less or lower than the common tubular SOFC enables less exotic materials of structure, thus cost saving [7].

There are many research works on developing tubular SOFC models such as a development of a dynamic model of SOFC for power system simulation using several types of software and also model for analyzing power system performances which consider all the losses or voltages drop in the model [12, 13]. Besides that, a nonlinear state space model of tubular SOFC to examine the dynamic behavior of SOFC for changes in input fuel, air pressure, and temperature was developed by Yutong et al. [14] and most of these researchers used MATLAB/Simulink environment in developing SOFC model due to its ability in analyzing the model for future power applications. The tubular types is receiving too much attention from researchers [15-17] while the modeling of planar SOFC is limited.

PSOFC is the new focus in renewable energy technology where the PSOFC system balances the manufacturing cost and also promises the prospective in achieving lower stack. The main purpose of this paper is to model PSOFC performances by using artificial neural network (ANN) approach. Normally, in the existing technology, in order to develop the model of fuel cell, it will take a longer period of time to study the dynamic behavior due its complex system and the chemical reactions inside the model. Therefore, ANN can help in reducing the time required during the fuel cell modeling process. Moreover, it is basically difficult to estimate the parameters for the fuel cell system. Therefore, neural network approach will provide well modelling advantages, does not required many investigation of parameters and it will be easier in extending the model for power system analysis study such as distributed generation and micro grid applications.

\section{ELECTROCHEMICAL EQUATIONS FOR PLANAR SOFC}

Electrochemical equations are important in analyzing the PSOFC reactions inside the cell and all of these equations are used to estimate current densities throughout the cell. PSOFC Simulink model can be developed by using the electrochemical equations and the input output data for ANN model can be obtained from the simulation of the PSOFC Simulink model. PSOFC voltage is calculated based on the reversible voltage and the sum of several losses from the polarization curve [18] which are the effects of activation, con-centration and ohmic losses $[19,20]$. The open circuit voltage $\left(E_{O C V}\right)$ or also known as the reversible cell voltage is acknowledged as a function of temperature and reactant concentration. The cell operating voltage $\left(V_{c e l l}\right)$ is equal to the subtraction of the open circuit voltage from the sum of losses shown as below [18]:

$$
V_{\text {cell }}=E_{O C V}-\sum\left(\eta_{\text {act }}+\eta_{\text {ohm }}+\eta_{\text {conc }}\right)
$$

The open circuit voltage can be obtained from the Nernst equation below [21]:

$$
\begin{aligned}
& E_{O C V}=E^{0}-R T / z F\left(\ln \left(P_{H 2} * P_{O 2}{ }^{0.5}\right) / P_{H 2 O}\right) \\
& \text { where; } E^{0}=-\Delta G^{0} / z F
\end{aligned}
$$

where $\Delta G^{\circ}$ is the Gibbs free energy change at standard state and $F$ refer to the Faraday's number. $n$ is the number of electrons formation in the reaction where the value of $n$ is two due to the number of two electrons transferred for every one mole of reacted hydrogen. Normally in fuel cell characteristics as well as in SOFC studies, the major losses are the ohmic polarization $\left(\eta_{\text {ohm }}\right)$, activation polarization $\left(\eta_{\text {act }}\right)$, and concentration polarization $\left(\eta_{\text {conc }}\right)$. The activation loss is the difference between ionic potential at the electrolyte and electronic potential at the electrode which is greater than the equilibrium potential [22]. Activation polarization for both electrodes, anode and cathode can be determined using equation (4) and (5) below [22]:

$$
\begin{aligned}
& \eta_{a c t, a n}=2 R T / z F\left[\sinh ^{-1}\left(I / 2 i_{o, a n}\right)\right] \\
& \eta_{a c t, c a}=2 R T / z F\left[\sinh ^{-1}\left(I / 2 i_{o, c a}\right)\right]
\end{aligned}
$$


In the above equations, $i_{o, a n}$ and $i_{o, c a}$ are the exchange current density for both anode and cathode. The ohmic polarization depends on the electrical resistance of the electrodes and the ion transport in the electrolyte and it is describe by the Ohm's Law as shown below.

$$
\eta_{\text {ohm }}=R_{\text {ohm }} i
$$

The ohmic resistance, Rohm can be written as [22]:

$$
R_{\text {ohm }}=\left[\left(\tau_{a n} / \sigma_{a n}\right)+\left(\tau_{e l} / \sigma_{e l}\right)+\left(\tau_{c a} / \sigma_{c a}\right)\right]
$$

Concentration polarization happens due to the reductions of reactant gas concentrations and can be determined by the following eequations [22]:

$$
\begin{aligned}
& \eta_{\text {conc,an }}=-(R T / 2 F) \ln \left[1-\left(I / i_{a s}\right)\right]+(R T / 2 F) \ln \left[1+\left[I\left(P_{H 2, a n}\right) /\left(P_{H 2 O, a n} \cdot i_{a s}\right)\right]\right] \\
& \eta_{c o n c, c a}=-R T / 4 F \ln \left(1-\left(I / i_{c s}\right)\right)
\end{aligned}
$$

where $i_{a s}$ and $i_{c s}$ are the current densities at electrode or electrolyte interfaces in which the partial pressure of gas is nearly zero and it can be define as [22]:

$$
\begin{aligned}
& i_{a s}=\left(2 \mathrm{FP}_{\mathrm{H} 2, \mathrm{an}}\right)\left(\mathrm{D}_{a n}^{e f f}\right) /\left(\mathrm{RT} \tau_{\mathrm{an}}\right) \\
& \left.i_{c s}=\left(4 \mathrm{FP}_{\mathrm{O} 2, \mathrm{ca}}\right)\left(\mathrm{D}_{c a}^{e f f}\right) /\left(\left[\left(\mathrm{P}_{\mathrm{ca}}-\mathrm{P}_{\mathrm{O} 2, \mathrm{ca}}\right)\right)\right) / \mathrm{P}_{\mathrm{ca}}\right]\left[\mathrm{RT} \tau_{\mathrm{ca}}\right]
\end{aligned}
$$

The output fuel cell voltage, $V_{f c}$ can be expressed as [22]:

$$
V_{f c}=N_{O}\left(E_{O C V}-\eta_{a c t, a n}-\eta_{a c t, c a}-\eta_{o h m}-\eta_{c o n c, a n}-\eta_{c o n c, c a}\right)
$$

The overall output voltage depends on the number of cells, $\left(N_{0}\right)$ used in the design. Equations (1)(12) are used to develop PSOFC model by using MATLAB/Simulink software as shown in Figure 1 and the parameters used in this developed model are shown in Table 1. The overall model of the PSOFC consists of seven subsystem which are partial pressure, open circuit voltage, activation polarization in anode, activation polarization in cathode, concentration polarization for both anode and cathode and also the ohmic polarization. The partial pressure equations can be found in El-Sharkh et.al [23].

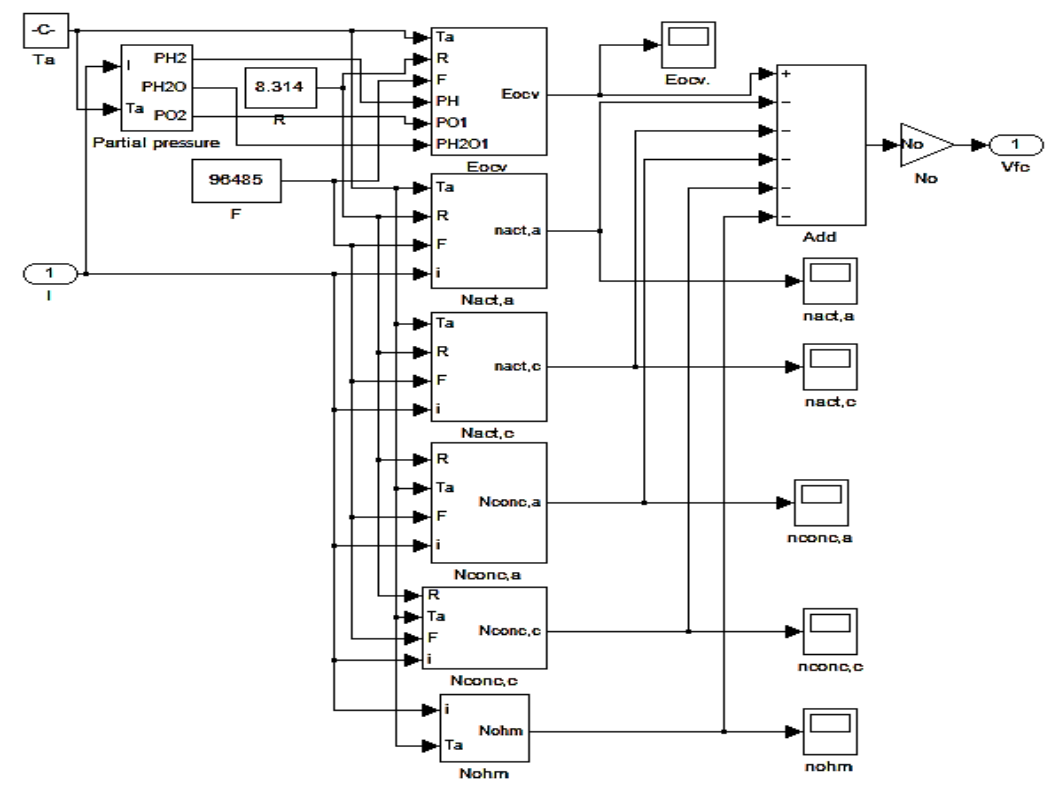

Figure 1. PSOFC Simulation Model in MATLAB/ Simulink [24] 


\begin{tabular}{|c|c|}
\hline Parameters & Values \\
\hline$i_{o, a n}\left(A m^{-2}\right)$ & 5300 \\
\hline$i_{o, c a}\left(A m^{-2}\right)$ & 2000 \\
\hline$\tau_{a n}(m m)$ & 700 \\
\hline$\tau_{e l}(m m)$ & 10 \\
\hline$\tau_{c a}(m m)$ & 50 \\
\hline$\sigma_{a n}(S / m)$ & $\left(9 \times 10^{7} / \mathrm{T}\right) \mathrm{e}^{-1150 / \mathrm{T}}$ \\
\hline$\sigma_{e l}(S / m)$ & $\left(3.34 \times 10^{4} / \mathrm{T}\right) \mathrm{e}^{-10300 / \mathrm{T}}$ \\
\hline$\sigma_{c a}(S / m)$ & $\left(4 \times 10^{7} / \mathrm{T}\right) \mathrm{e}^{-1200 / \mathrm{T}}$ \\
\hline$P_{c a}(\mathrm{~atm})$ & 1 \\
\hline$P_{a n}(a t m)$ & 1 \\
\hline $\mathrm{D}_{\text {an }}^{\text {eff }}\left(m^{2} s^{-1}\right)$ & $3.5 \times 10^{-5}$ \\
\hline $\mathrm{D}_{\boldsymbol{c a}}^{\boldsymbol{e f f}}\left(m^{2} s^{-1}\right)$ & $7.3 \times 10^{-6}$ \\
\hline$P_{H 2, a n}(\% m o l)$ & 97 \\
\hline$P_{H 2 O, a n}(\% m o l)$ & 3 \\
\hline $\mathrm{P}_{\mathrm{O} 2, \mathrm{ca}}(\% m o l)$ & 21 \\
\hline$\Delta G^{0}$ & $237 \mathrm{kJmol}^{-1}$ \\
\hline
\end{tabular}

\section{ANN INPUT AND OUTPUTS DATA}

An artificial neural network is a mapping network or technique that were able to compute some functional relationship between its input and output. Nowadays, the neural network have become a very importance tool or technique in some of the application as it were used to solve a wide variety of problems. Moreover, ANNs able to give results for non-linear problems very quickly once the training process is over [25-27]. Therefore, the performances of the PSOFC can be model by implementing the ANN approach employing MLP and RBF neural network techniques. The applications of the ANN is a relatively simple technique with a rapid response time and the system is considered suitable to determine the performances of the PSOFC.

In the first part of the simulation, the PSOFC system have been design and model in the MATLAB/Simulink software in order to obtain the set of inputs and outputs for about 1200 data. These data later will be used for the next task which is to construct the PSOFC model using artificial neural network environment. The set of input and output data were divided into 3 parts which are the data of training, testing and validation. For ANN model, about $70 \%$ samples of data were used for training, 15\% for testing and $15 \%$ for validation. For this paper, there are two inputs data involved which are the load current and temperature. The set of input data will be fed to the MLP neural network using sigmoid activation function in the hidden layer. There are two output neurons for the PSOFC system which are the output voltage and also the output power. Then number of neurons in hidden layer effects the overall neural network performances as small amount of neuron may have prohibited the network from correctly and effectively mapping the input and output. Table 2 shows the parameters used in MLP and RBF neural network and Figure 2 shows the basic arrangement of the MLP and RBF architecture.

Table 2. MLP and RBF Parameters

\begin{tabular}{ccc}
\hline Methods & MLP & RBF \\
\hline Goal (MSE) & Not applicable & 0 \\
Inputs & 2 & 2 \\
Outputs & 2 & 2 \\
Hidden layer & 1 & 1 \\
Activation function in hidden layer & Sigmoid & Gaussian \\
Spread & Not applicable & 8 \\
Training & 840 & 840 \\
Testing & 180 & 180 \\
\hline
\end{tabular}




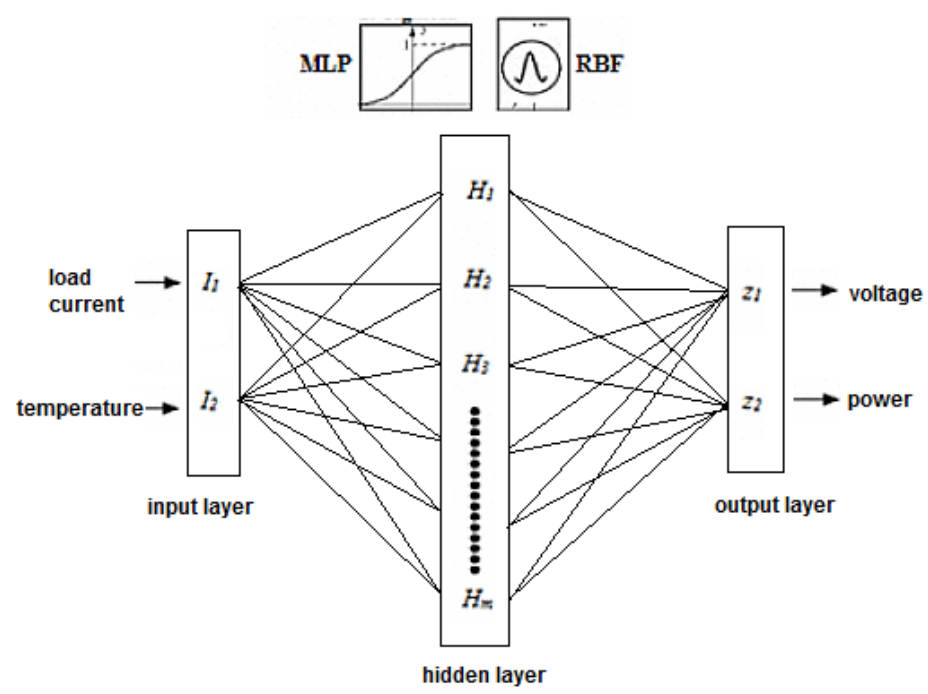

Figure 2. The three layers architecture of MLP and REF neural networks

Generally, normalization process is a process that transforming all the data or variable of a certain parameter to a specific range or interval like 0 and 1 or between -1 to +1 . When there is big different in range, normalization is required so that all the inputs are at a comparable range. The data normalization is one of the important step for any analysis of the input sample from many situation in putting the data into a close range. In the ANN system, the existence of the activation function that used in the hidden layer with certain range made the data normalization process is one of the initial step before proceed to the next step. For sigmoid function, the range lies between 0 to 1 so the data will be normalized within the range in order to ensure the regression result lies within the specific area. Based on this paper, the normalization of data into p.u. from the range 0 until 1 can be done by using the equation below,

$$
Z_{i}=\left(X_{i}-X(\min )\right) /(X(\max )-X(\min ))
$$

where,

$Z_{i}=$ the normalized data

$X=$ the actual data

The performance of the proposed ANN technique is evaluated in terms of the maximum error $\left(e_{\max }\right)$ and root mean square (RMS) error $\left(e_{r m s}\right)$ which are given mathematically by the following equations:

$$
\begin{aligned}
& e_{\text {max }}=\max \left|\mathrm{T}_{\mathrm{q}^{-}} \mathrm{O}_{\mathrm{q}}\right|, \mathrm{q}=1,2,3 \ldots, \mathrm{n} \\
& e_{r m s}=\sqrt{ }\left(1 / \mathrm{n} \sum_{q=1}^{n}\left(\mathrm{t}_{\mathrm{q}}-\mathrm{O}_{\mathrm{q}}\right)^{2}\right)
\end{aligned}
$$

where $\mathrm{T}_{\mathrm{q}}=\left[\mathrm{t}_{\mathrm{q} 1}, \mathrm{t}_{\mathrm{q} 2}, \ldots, \mathrm{t}_{\mathrm{qmax}}\right]$ is the target vector, $\mathrm{O}_{\mathrm{q}}=\left[\mathrm{O}_{\mathrm{q} 1}, \mathrm{O}_{\mathrm{q} 2}, \ldots, \mathrm{O}_{\mathrm{qmax}}\right]$ is the output vector of the output layer, and $\mathrm{n}$ is the number of neurons in the output layer. This error function is generated when the desired output of a network is compared with the actual output of a system.

\section{RESULTS AND ANALYSIS}

The results of the comparison between MLP and RBF for modeling the PSOFC performances are presented. In this section, the performance of the PSOFC system was determine by comparing the results of the MLP and RBF neural network model using a set of inputs and outputs data obtained from the PSOFC model simulation results using MATLAB/Simulink explained before. There are two main results that have been discussed which are the regression analysis and the network errors. The regression analysis is about the statistical process for estimating the relationship among the variables. This statistic will shows the distribution of data lies to the certain point in the regression process. The regression analysis of the MLP and RBF neural network between the outputs and responding targets are shown in Figures 3 and 4, respectively. 


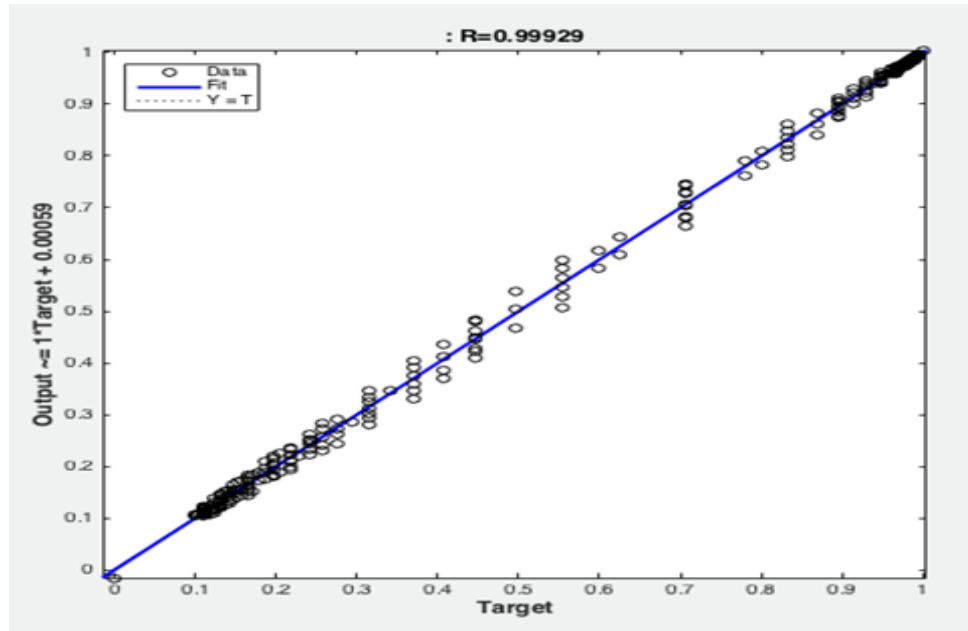

Figure 3. Regression of PSOFC model using MLP

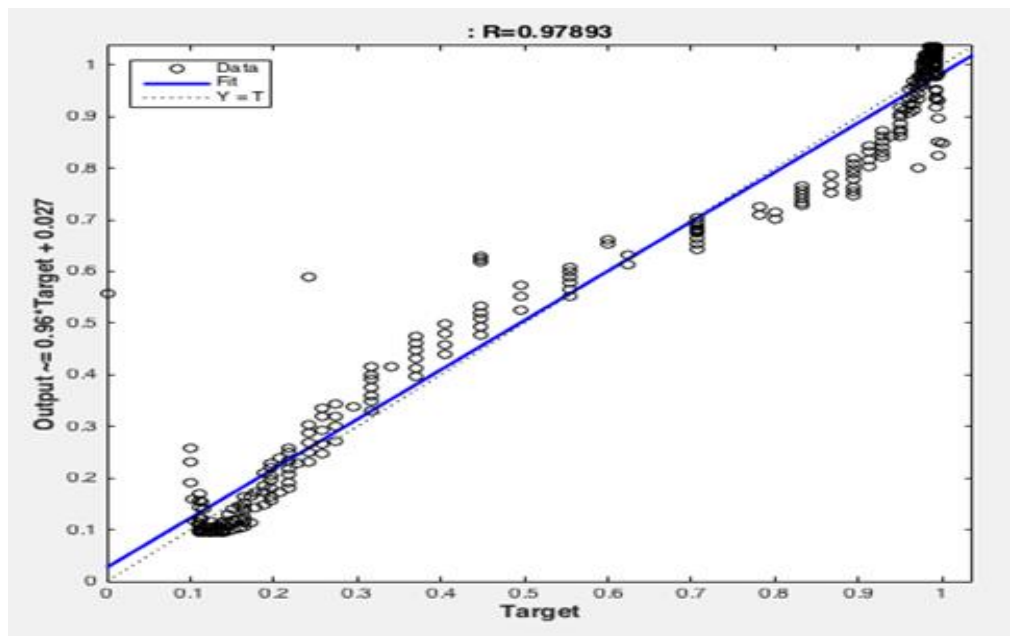

Figure 4. Regression of PSOFC model using RBF

The correlation coefficient (R) for both ANN types are almost equal to 1 that indicates the regression have the strong correlation between the actual output data and target data of neural output. The MLP neural network indicates the best value of R which is 0.99929 followed by RBF function which is 0.97893. From the regression results, it can observed that the MLP network employing sigmoid activation function shows the best result as the data are converges along the best fit line. The maximum and RMS errors are then calculated using equations (14) and (15) and Table 3 summarizes the network errors with bold figures represent the best testing RMS errors.

Table 3. Performance of MLP and RBF Neural Networks Testing Stage

\begin{tabular}{ccccc}
\hline \multirow{2}{*}{ Output Data } & \multicolumn{2}{c}{ Sigmoid (MLP) } & \multicolumn{2}{c}{ Gaussian (RBF) } \\
& $e_{\max }$ & $e_{\text {mms }}$ & $e_{\max }$ & $e_{\text {mms }}$ \\
\hline Power & 0.0692 & 0.0328 & 0.2822 & 0.0823 \\
Voltage & 0.0623 & 0.0145 & 0.1021 & 0.0755 \\
\hline
\end{tabular}

From Table 3, it can be observed that the MLP network always achieves the best classification of the RMS errors for the two of the outputs data of PSOFC system. The MLP network is good in determining the testing stage for the performance of PSOFC system with the lowest RMS error. Based on the results, the MLP neural network shows the lowest value of the maximum error for power and voltage with the values of 
0.0692 p.u and 0.0623 p.u, respectively while for RBF neural networks, the maximum error for both power and voltage are 0.2822 p.u and 0.1021 p.u, respectively. MLP is also good in minimizing the maximum error for the testing stage with the value of $0.0328 \mathrm{p}$.u and $0.0623 \mathrm{p} . \mathrm{u}$ for both power and voltage compared to RBF with the higher values. This indicates that the MLP network with Sigmoid activation function in the hidden layer has the best results and able to give the best classification for the power and voltage values. It can be conclude that the trained MLP neural network can correctly predict the performances of PSOFC with the minimal errors.

\section{CONCLUSION}

The investigation of PSOFC performances by using ANN approach shows the performance of this fuel cell by comparing the results from different types of ANN which are the radial basis function and multilayer perceptron. Through the regression analysis it can be clearly seen the correlation amongst variables has been successfully estimated statically. It has been known practically that MLP is more superior than RBF but this is true for certain application as generically RBF is also powerful to yields best regression on given set data input and output depending how the training been conducted. To have minimum error for any network is utterly prominent thus it can be concluded through this investigation that MLP network does its best performance with showing less errors. In a nutshell, the MLP neural network with the Sigmoid activation function in the hidden layer gives the best result compared to the RBF as the regression shows the best fitting result with minimal RMS errors of 0.0692 p.u for power and 0.0623 p.u for voltage.

\section{ACKNOWLEDGEMENTS}

This work was supported by TIER 1 grant (U862) of Universiti Tun Hussein Onn Malaysia (UTHM), Power Energy Focus Group, Advanced Technology Centre (ATC), Faculty of Engineering Technology, UTHM and Green and Sustainable Energy, Faculty of Electrical and Electronics Engineering (GSEnergy), UTHM.

\section{REFERENCES}

[1] S. O. T. Ogaji, et al., "Modelling fuel cell performance using artificial intelligence," Journal of Power Sources, vol. 154, pp. 192-197, 2006.

[2] Y. Qi, et al., "Dynamic modeling of solid oxide fuel cell: The effect of diffusion and inherent impedance," Journal of Power Sources, vol. 150, pp. 32-47, 2005.

[3] M. A. Ansari, et al., "Optimization of electrochemi-cal performance of a solid oxide fuel cell using Artificial Neural Network," 2016 International Conference on Electrical, Electronics, and Optimization Techniques (ICEEOT), Chennai, pp. 4230-4234, 2016.

[4] G. Goodstal, "What is Fuel Cell," 2nd Ed. United States of America. Delmar Cengage Learning, 2013.

[5] K. Nice and J. Strickland, "How fuel cell works," 2000. Available: qfuels/fuel-cell.htm.

[6] Nedstack, “About the Fuel Cell Types,” 2001. Available: http://www.nedstack.com/technology/fuel-cell-types.

[7] R. Zogg, et al., "Emerging technologies: using solid-oxide fuel cells for dis-tributed generation," ASHRAE J.l, vol. 48, pp. 116-118, 2006.

[8] U. G. Bossel, “Solid oxide fuel cells III," S.C. Signal, H. Iwa-hara (Eds.), The Electrochemical Society Proceedings Series, Pennington, NJ, USA, PV 93-4, pp. 833, 1993.

[9] "Fuel cell handbook," 7th ed. U.S. DOE, National Energy Tech-nology Laboratory, 2004.

[10] K. P. Recknagle, et al., "Three-dimensional thermo-fluid electrochem-ical modeling of planar SOFC stacks," Journal of Power Sources, vol. 113, pp. 109-114, 2003.

[11] X. Mengxue and L. Xi, "Modeling and temperature distribu-tion analysis of a single cell in cross-flow planar solid oxide fuel cell," 2015 Chinese Automation Congress (CAC), Wuhan, pp. 1448-1451, 2015.

[12] C. Wang and M. H. Nehrir, "A physically-based dynamic model for solid oxide fuel cells," IEEE Trans. Energy Conversion., vol. 22, pp. 887-897, 2007.

[13] Y. H. Liu, et al., "Application of SOFCs to Electric Power System," 2011 Asia-Pacific Power and Energy Engineering Conference, Wuhan, pp. 1-4, 2011.

[14] Q. Yutong, et al., "Nonlinear state space modeling and simulation of a SOFC fuel cell," American Control Conference, pp. 2534-2538, 2006

[15] Y. Iida, et al., "Development of an SOFC dynamic simulation environment," Proceedings of SICE Annual Conference, pp. 3125-3127, 2010.

[16] S. Fedakar, et al., "Modeling and simulation of SOFC using PSCAD," Eurocon 2013, Zagreb, pp. 1058-1065, 2013.

[17] A. A. Salam, et al., "Dynamic modeling and simulation of Solid Oxide Fuel Cell system," 2008 IEEE 2nd International Power and Energy Conference, Johor Bahru, pp. 813-818, 2008.

[18] A. Pramuanjaroenki, et al., "Mathematical Analysis of Planar Solid Oxide Fuel Cells," International Journal of Hydrogen Energy, vol. 33, pp. 2547-2565, 2008. 
[19] J. Padulles, et al., “An Integrated SOFC Plant Dynamic Model for Power Systems Simulation,” Journal of Power Sources, vol. 86, pp. 495, 2000.

[20] C. Boccaletti, et al., "Simulations models of fuel cell systems," Proc. ICEM, Electrical Machines, Chania, Greece, pp. 6, Sep 2006

[21] J. T. Kuo, et al., "Using Artificial Neural Network for Reservoir Eutrophication Prediction," Ecological Modeling, vol. 200, pp. 171-177, 2007.

[22] A. Chaisantikulwat, et al., "Modelling and control of planar anode-supported solid oxide fuel cell," Computers \& Chemical Engineering, vol. 32, pp. 2365-2381, 2008.

[23] M. Y. El-Sharkh, et al., "A dynamic model for a stand-alone PEM fuel cell power plant for residential applications," Journal of Power Sources, vol. 138, pp. 199-204, 2004.

[24] N. A. Zambri, et al., "Performance comparison of dynamic models of proton exchange mem-brane and planar solid oxide fuel cells subjected to load change," International Review on Modelling and Simulations (IREMOS), vol. 4, pp. 3402-3409, 2011.

[25] M. Beccali, et al., "Forecasting daily urban elec-tric load profiles using ANNs," Energy Conv. And Manag., vol. 45, pp. 2879-2900, 2004.

[26] S. A. Kalogirou, "Applications of ANNs in energy systems: a review," Energy Conv. Manag., vol. 40, pp. 10731087, 1999.

[27] M. Ilunga and D. Stephenson, "Infilling stream flow data using feedforward back-propagation (BP) ANNs," Water SA, vol. 31, pp. 171-176, 2005.

\section{BIOGRAPHIES OF AUTHORS}

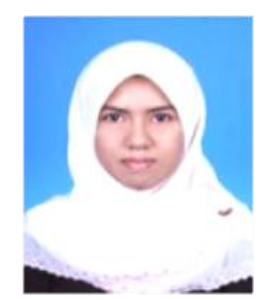

Nor Aira Binti Zambri received her BSc from Universiti Kebangsaan Malaysia in 2007 and MEng from Universiti Teknologi Malaysia in 2010, respectively. She received her $\mathrm{PhD}$ on electrical power engineering from Universiti Kebangsaan Malaysia (UKM) in 2015. Currently, she works as senior lecturer in Universiti Tun Hussein Onn Malaysia and she can be reached at aira@uthm.edu.my. Her main research interests are artificial intelligence, distributed generation and renewable energy systems.

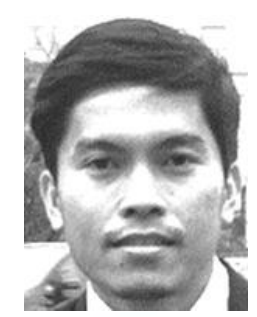

Dr. Norhafiz Bin Salim obtained his Bachelor`s degree from Universiti Teknikal Malaysia Melaka (UTeM) Malaysia in 2007, Msc. degree from Universiti Teknologi Malaysia (UTM), in 2009 and Dr. Eng. degree from Yokohama National University (YNU), Japan in 2017. Since 2007 he has been with UTeM as a tutor, lecturer and currently a senior lecturer in the Department of Electrical Engineering. His current research is centered on frequency/voltage stability assessment and analysis with distributed energy resources.

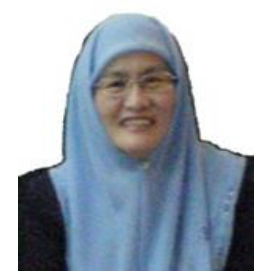

Azah Mohamed received her BSc from the University of London in 1978 as well as her MSc and $\mathrm{PhD}$ from Universiti Malaya in 1988 and 1995, respectively. She is a professor in the Department of Electrical, Electronic and Systems Engineering, Universiti Kebangsaan Malaysia. Her main research interests are power quality, artificial intelligence, and renewable energy systems. She is a senior member of IEEE. She can be reached at azah@eng.ukm.my.

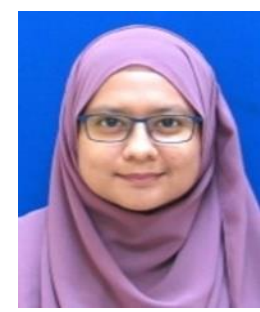

Ili Najaa Aimi Mohd Nordin obtained her B. Eng. Degree in Electrical-Medical Electronics Engineering and Ph.D degree in the field of Soft Robotics Engineering from Universiti Teknologi Malaysia, Malaysia. Currently, she is working as a lecturer in the Department of Electrical Engineering Technology, Faculty of Engineering Technology, Universiti Tun Hussein Onn Malaysia (UTHM). Her main research interests are in the areas of Electronics, Soft Robotics, Rehabilitation Robotics, Machine Learning and Wireless Monitoring. She is currently the head researcher of Cybernetics Research Group (CRG) in the UTHM, a member of Board of Engineer Malaysia (BEM), Institute of Engineers Malaysia (IEM) and Malaysia Board of Technologists (MBOT). 